\title{
The Brush Busters Success Story
}

\author{
Want producers to adopt new research? This Texas program offers an effec- \\ tive blueprint for successful technology transfer from scientist to landowner.
}

\author{
By Allan McGinty and Darrell N. Ueckert
}

Editor's Note: The high level of satisfac tion with the efficacy and cost effectiveness of individual plant treatments expressed by four west-central Texas ranchers, coupled with detailed data on treatment efficacy and costs from research and demonstra tion plots were the catalysts that prompted range scientists at the Texas $A \& M$ University Agricultural Research \& Extension Center at San Angelo to design and implement a special program to "mar ket" do-it-yourself brush control technolo gy to ranchers. Here, they share their story on the development of the program called "Brush Busters."

The transfer of agricultural technology from scientist to ranchers and rangeland resource managers has always been a challenge. For example, for decades research has indicated that cattle growth implants provide a re- turn of several dollars for every dollar invested. Despite an almost guaranteed positive return on the investment, only $21 \%$ of beef producers in southcentral Texas used implants in 1987. Similar low adoption rates are found for grazing management practices.

In spite of the wealth of research and the emphasis of Extension programs on flexible stocking to protect rangeland health, almost half the respondents in a 1990 survey of Texas ranchers indicated they do not make adjustments in livestock numbers or use rest-rotation grazing. The failure of many rangeland owners/managers to use proper grazing management is not because of the lack of technology and information, but rather due to their failure to adopt and utilize cur- rently available technology and information.

This situation exists for other technologies such as weed and brush control. Many ranchers ignore woody plant problems until the stands are mature and dense. By this time, major declines in forage, wildlife habitat, livestock production, and net income have occurred.

The usual approach is to hire a contractor with heavy machinery or an aerial herbicide applicator to apply an expensive reclamation treatment. Often, there is no plan for maintenance treatments, and the process is repeated when the brush has again become mature and dense. In many cases, the brush is allowed to increase to the point where serious, and some-

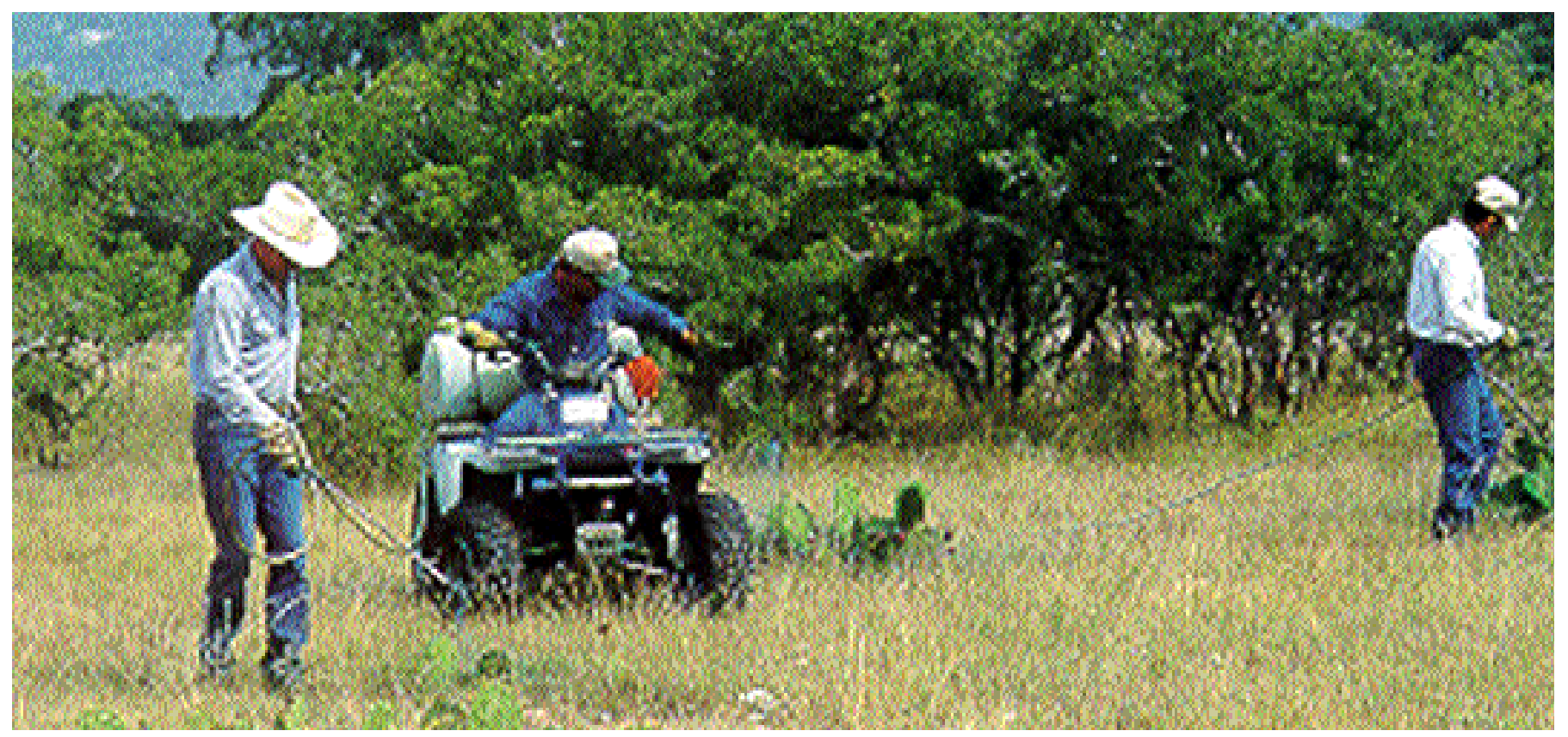

Fig. 1. ATV's make excellent spray platforms. This 4-wheel ATV, equipped with a 25-gal spray tank and 12-volt "Shurflo" pump, supports three spray guns, and covers a 40-ft-wide swath. 
times irreversible damage occurs to soils, forage and wildlife habitat.

The traditional approach of infrequent treatment of dense brush requires very little managerial or technical skill. This strategy is not economically sound because livestock and wildlife production and net revenue decrease as brush thickens and matures. The effective treatment life of expensive, reclamation treatments is usually not sufficient to recover treatment costs.

The traditional approach described above is not ecologically sound because as brush matures and thickens, the abundance and productivity of desirable species decrease and they are often replaced by less desirable or noxious species. Topsoil may be eroded, which permanently decreases the potential of the land to produce forage and cover.

Moreover, many conventional reclamation brush treatments are non-selective, and negatively impact biological diversity and multiple use values of the land for wildlife habitat, livestock production, recreation, and aesthetics. These treatments may present other economic and ecological risks, including inadequate plant kill to meet the landowners' management objectives or expectations; drought that delays or nullifies the benefits of a brush control treatment; and potential liability for damage to neighbors' forage, crops, or property.

The increase in brush cover and density in Texas has exceeded the control of these plants because of:

- rising costs of conventional, reclamation brush control treatments;

- failure of ranchers to use follow-up treatments to extend overall treatment life;

- failure of landowners to recognize and treat brush infestations early;

- failure of reclamation treatments to meet the "plant kill" and "longevity" expectations of landowners;

- increasing recognition of the importance of woody plants and forbs for wildlife;

- new property tax laws that increased landowner incentives for providing wildlife habitat;

- decreasing oil and gas revenues for ranchers; and

- changes in demographics increasing rangeland owners with nontraditional ownership goals.

In Texas, the decrease in use of conventional brush control methods by ranchers over the last 25 years has been shadowed by increasing interest in "do-it-yourself" brush control methods.

Many effective control methods are available for selective control of brush seedlings, saplings, and mature brush. The efficacy, economics, labor-efficiency and acceptability of these individual plant treatments have been greatly improved by several new innovations, including all-terrain vehicles (4-wheelers) equipped with sprayers and electric pumps (Fig. 1); light-

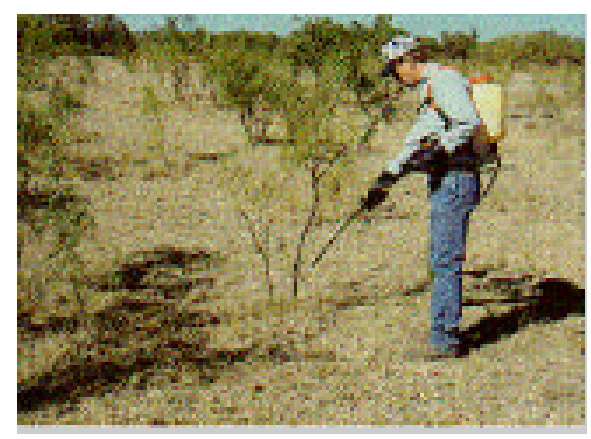

Fig. 2. Backpack sprayers are relatively inexpensive and can be used for indi vidual-plant stem sprays or leaf sprays.

weight, backpack sprayers (Fig. 2); highly effective herbicides and spraymarking dyes; and simplification and refinement of application techniques.

However, the rate of adoption and learning of the available individualplant-treatment technology was slow because ranchers were inexperienced with the technology and unaware of the high levels of plant kill possible with individual plant treatments. Most ranchers, rangeland scientists and resource management specialists thought individual-plant-treatment technology was too labor intensive, impractical, and cost prohibitive on large acreages.

\section{Brush Busters Program Introduced}

To address this lack of understanding, Brush Busters programs were designed to appeal to the common sense of rangeland owners/managers. The goal of Brush Busters was to expedite the adoption of individual plant treatments for brush control in Texas.

Brush Busters emphasized that brush should be controlled:

1) before debilitation of the forage and soil resources occurs;

2) while brush is in its most vulnerable growth stage (i.e. seedlings or saplings); and

3) before brush plants produce seeds that will re-infest rangeland or pastures.

To accomplish this goal, an action plan was developed in the autumn of 1994, that included the following steps:

- develop identity for the program by giving it a unique name and logo (Fig. 3);

- focus efforts on three major species, honey mesquite in year 1 , juniper in year 2, and pricklypear in year 3;

- refine and improve the available technology where necessary;

- develop layman-friendly technical guides, videos, CD-ROM programs and web pages;

- establish highly visible demonstration/research plots to showcase control methods for each species;

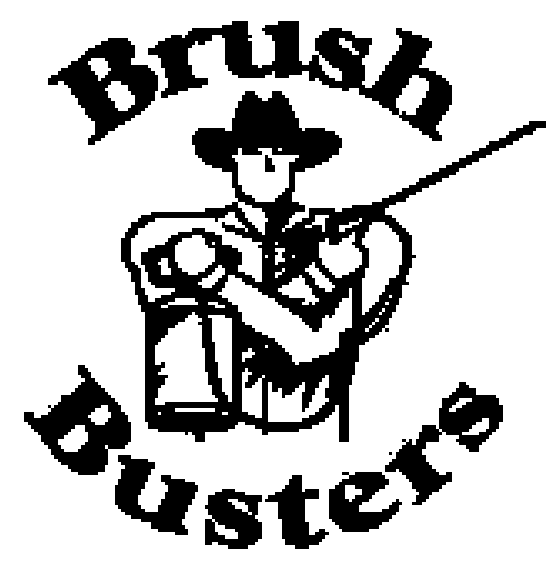

Fig. 3. Brush Busters logo. 
- document treatment costs and efficacy, as well as the labor and herbicide used for all Brush Busters control methods;

- enhance knowledge and adoption of the technology by rangeland owners/managers through workshops, field days, tours, news releases, and county-level programs; and

- develop mutually beneficial partnerships with industry, agencies, commodity and special interest groups to leverage the initial efforts and resources invested in Brush Busters.

\section{Factors For Success}

During the planning process, three factors were seen as critical to the recognition, acceptance and adoption of the Brush Busters program. First, the marketing program needed a unique identity. With the assistance of the Department of Agricultural Communications at Texas A\&M University, the Brush Busters name and logo were selected (Fig. 3).

Second, because treatments had to be safe and highly effective, a "standard of performance" for treatments was established. All control methods selected for inclusion in the Brush Busters program had to provide $70 \%$ or greater root kill of the treated plants.

And finally, the instructional/educational materials for selected methods had to be brief and non-technical.

Another critical component of the Brush Busters program was the establishment of large-scale demonstration/research plots to "showcase" control methods. Plots were established in highly visible locations along major highways in five west-central Texas counties each summer during 1995 (mesquite), 1996 (cedar) and 1997 (pricklypear). At each location, teams of five to seven workers applied the various Brush Busters methods. The demonstration sites were identified by 4- $\mathrm{x} 8$-ft signs, visible to all motorist traveling the highway. All signs were professionally designed and constructed (Fig. 4).

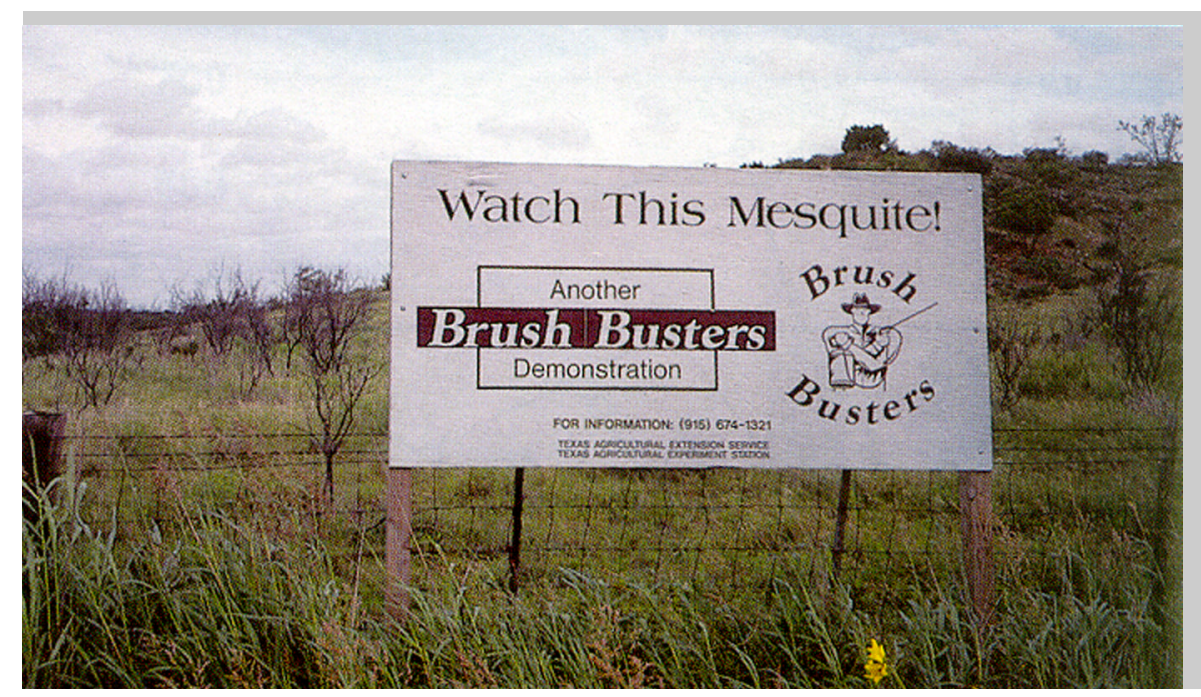

Fig. 4. All Brush Busters research/demonstration plots were identified by large, pro fessionally designed and painted signs.

Data recorded for each treatment included the labor, machine time, amount of spray mixture used, number of plants treated, and total acres treat-

ed. Costs per plant and per acre (Fig. 5) were calculated for all methods as well as the quantity of herbicide used (Fig. 6).

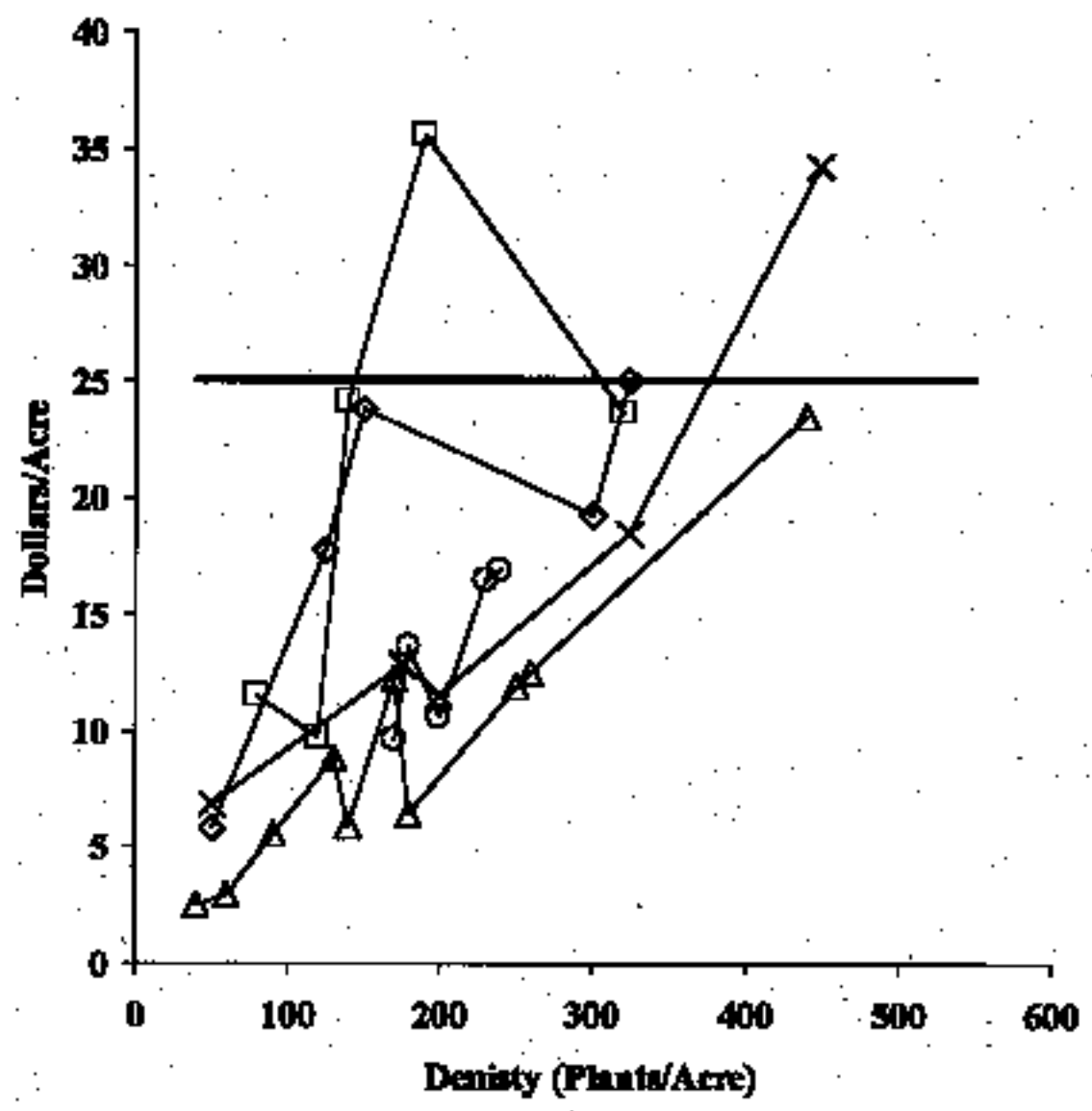

Fig. 5. Cost per acre for Brush Busters treatment methods as a function of plant den sity. The bold, horizontal line represents the approximate cost for aerial broadcast herbicide treatments of mesquite and pricklypear. 


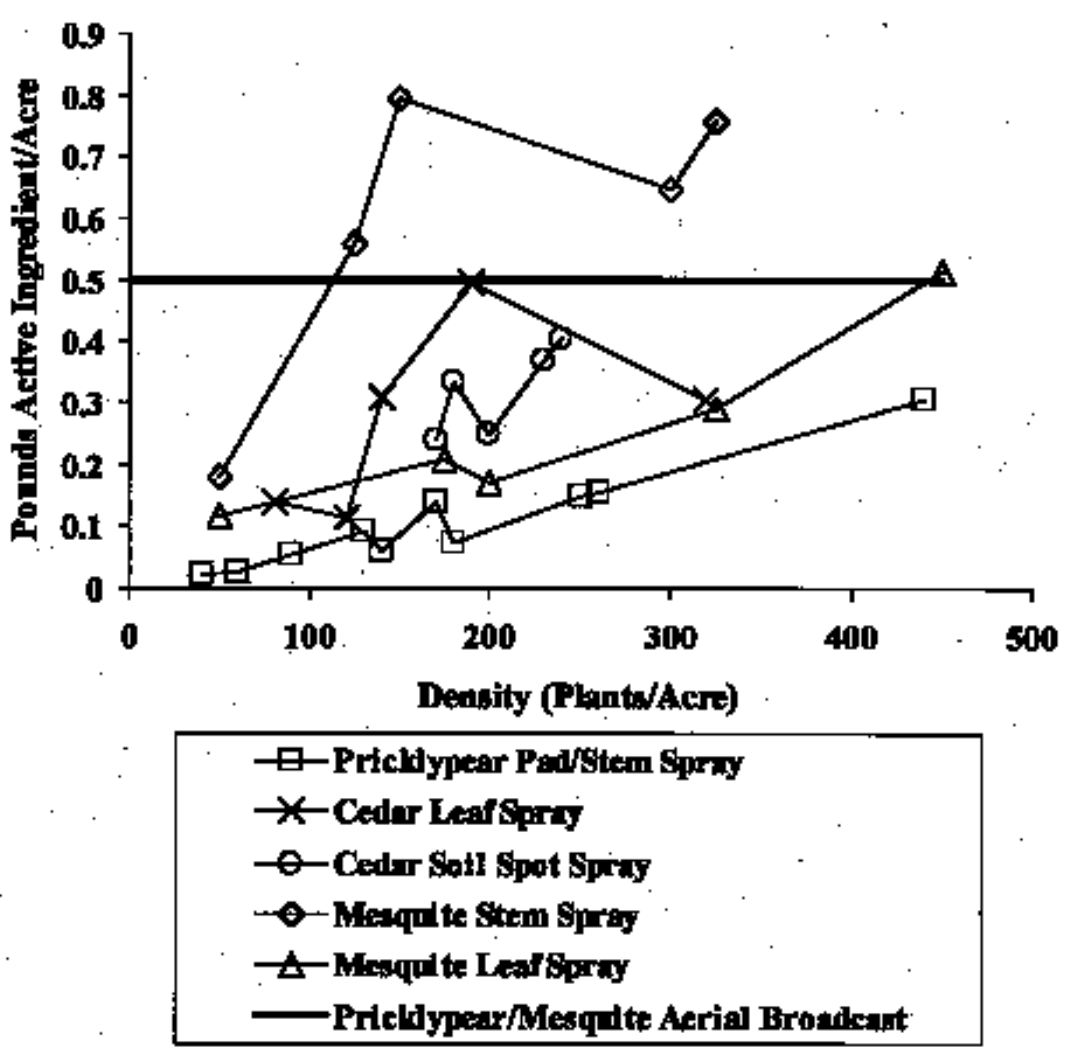

Fig. 6. Quantity of herbicide (lb active ingredient/acre) used by Brush Busters treat ment methods as a function of plant density. The bold, horizontal line represents the amount of herbicide applied per acre to control mesquite or pricklypear using aerial broadcast sprays.

Mesquite and cedar plots were evaluated for root kill 1 and 2 years posttreatment. Pricklypear plots were evaluated for root kill 1, 2 and 3 years after treatment. The data obtained from these large-scale demonstrations and the sites themselves were used to promote and educate potential users about Brush Busters methods (Table 1).

In addition to the demonstration/research plots, dozens of smaller, county-level demonstrations were established by county Extension agents and Extension specialists in the western

half of the state. Participating counties were supplied with all herbicides needed to treat each demonstration area, detailed instructions on how to establish, evaluate and publicize the demonstration, and a 4- x 2-ft Brush Busters sign for each demonstration.

\section{Information \& Education Materials Kept Simple}

All Brush Busters technical guides were designed to be brief and nontechnical.The educational materials produced for each target species in-

Table 1. Mortality of mesquite, cedar and pricklypear, 2 or $3 \mathrm{yr}$ after treatment with Brush Busters methods. These values represent the average, standard error and range of 5 locations for each species and method.

\begin{tabular}{|c|c|c|}
\hline Species/Method & Rootkill (\%) & Range (\%) \\
\hline Mesquite/Stem Spray & $80 \pm 11$ & 61 to 90 \\
\hline Mesquite/Leaf Spray & $80 \pm 12$ & 61 to 93 \\
\hline Juniper/Soil Spot Spray & $93 \pm 7$ & 84 to 99 \\
\hline Juniper/Leaf Spray & $91 \pm 10$ & 76 to 99 \\
\hline Pricklypear/Pad-Leaf Spray & $93 \pm 10$ & 67 to 99 \\
\hline
\end{tabular}

cluded: a single-page, tri-fold pamphlet that describes a 3 -step process for using each Brush Busters control method; a single-page, tri-fold pamphlet for each species that helps users estimate the cost of each Brush Busters control method; and a 10-15 min. video for each target species which demonstrates the respective Brush Busters treatments.

For each method, the proper procedures for selecting and preparing the spray equipment, and for mixing and applying the sprays are clearly detailed. To assure that the brochures and videos were user friendly, "recipe" charts were included to show how many oz, pt, or qt of each herbicide and spray adjuvant to use for three popular spray tank sizes $(3,14$ and 25 gal).

Brush Busters was also made available on the Internet. Through TEXNAT (Texas Natural Resource Web http://texnat.tamu.edu) individuals can obtain all of the information contained in the pamphlets as well as telephone numbers for suppliers of the recommended herbicides and spray equipment. The cost and control data from the Brush Busters research/-demonstration plots are also available. The web site gives phone numbers and email addresses for answers to specific questions or comments from landowners/managers (915-653-4576;

a-mcginty@tamu.edu;

d-ueckert@tamu.edu).

Because mesquite is the major brush plant in Texas, a CD-ROM program was developed for the "How to Beat Mesquite" program. This program contained video, sound, graphics and text, allowing the user to access the specific information required. The CD-ROM was provided at no cost to landowners by Dow AgroSciences.

Each County Extension Agent in Texas that had mesquite, cedar or pricklypear in their county received a Brush Busters notebook. The notebook contained a list of suppliers of the herbicides and equipment used in the Brush Busters program, copies of all Brush Busters leaflets, background information on mesquite, cedar and pricklypear, herbicide labels, press re- 
leases, demonstration guides and answers to the most commonly asked questions.

It was not possible to accomplish all of the goals and tasks described above using only the resources available through the Texas Cooperative Extension and Texas Agricultural Experiment Station. Thus, partnerships were formed with industry (Dow AgroSciences LLC, Hi-Pro Animal Health, and Dupont Agricultural Products), as well as with other agencies (Natural Resources Conservation Service, Texas Department of Agriculture, etc.).

These partnerships were used to disseminate Brush Busters information to landowners/managers. Of special importance was the partnership with Dow AgroSciences, which helped print and distribute Brush Busters brochures, videos, CD-ROMs, and notebooks, and supported tours, field days and other educational activities.

\section{Did The Program Work?}

Quantifying the adoption of range management technology in a privateland state is difficult because there are no public records of acres treated and the target species, and quantities of herbicide sold are held as proprietary information by the manufacturer or distributor.

Fortunately, Dow AgroSciences allowed access to their sales data, and it was possible to estimate acres of mesquite treated with the two recommended Brush Busters methods from 1995 to 1999.

Based on the assumption that most mesquite infestations treated with Brush Busters methods averaged about 125 plants/acre, it was estimated that the Brush Busters mesquite stem spray and leaf spray were used on 247,600 and 155,820 acres, respectively, in Texas during 1995 (Fig. 7). Estimated acreage increased to 433,024 acres of mesquite stem sprayed (a 74\% increase) and 181,090 acres leaf sprayed (a 16\% increase) in 1999. Total acreage treated by both methods in 1999 increased an estimated 52\% compared to 1995 .

Only in 1997 was there a significant

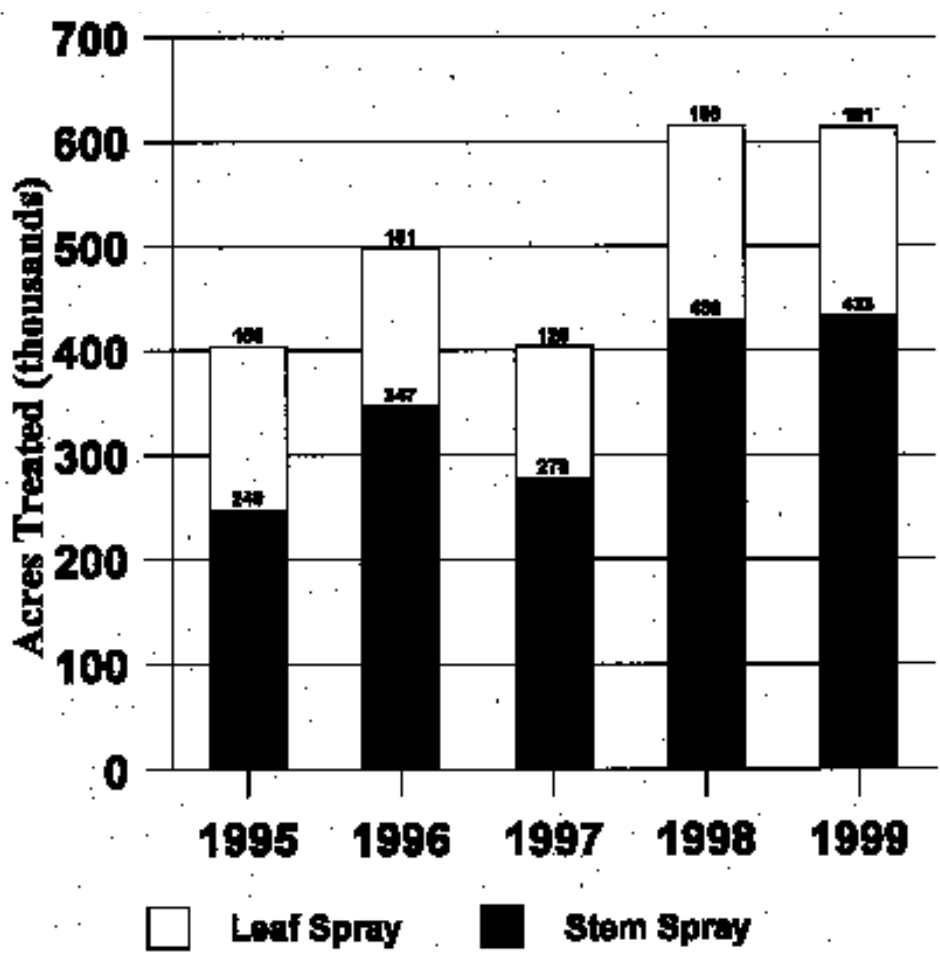

Fig. 7. Estimated acres of mesquite treated with Brush Busters stem and leaf sprays dur ing 1995-1999.

decrease in the acreage treated by Brush Busters methods compared to the preceding year. This occurred because conditions were very unfavorable for mesquite control, especially leaf spraying, in 1997. Brush Busters educational programs, media releases, etc. encouraged users not to spray that year.

Based on these estimates and an average \$25/acre cost for broadcast aerial spraying, in 1999 alone the acreage of mesquite treated with the Brush Busters methods saved landowners an estimated $\$ 8.7$ million in treatment costs. It also reduced the quantity of herbicide used by $20 \%$ as compared to using aerial broadcast spraying.

Why was the Brush Busters program successful? Based on a 1999 statewide survey of county Extension agents in Texas, several reasons were clear. The top four included effective and predictable kill, relatively low cost, simple and easily available information, and the environmental safety and selectivity of methods used.

There are limitations to the Brush Busters program. Individual landowners usually apply the treatments. They must do so properly to achieve expect- ed results. The methods used are generally not effective on large, mature plants. Also, treatment costs and the quantity of herbicide used increases significantly as the size and density of the brush increases. Success of these methods depends on early detection of brush problems and effective education of users on the proper and appropriate uses of Brush Busters methods.

With continued changes in the demographics of rangeland owners, ever-increasing urban encroachment, and fragmentation of rangelands there will be an increased need for highly selective, safe, environmentally friendly individual plant treatments to manage brush. These treatments will, in general, be applied by individual landowners, not commercial applicators.

To ensure the proper and effective use of these individual plant treatments, technology transfer programs must consider the end user. Educational programs must be simple, easy to understand, and readily available. They must use only treatments that are selective, highly effective, provide consistent results, and environmentally friendly. These were the goals of the Brush Busters program. 
Authors are, respectively: Professor and Extension Range Specialist, Texas Cooperative Extension, and Regents Fellow and Professor, Texas. Agric. Exp. Sta., US Hwy 87 North, San Angelo, Tex. 76901.

\section{Additional References}

Hanselka, W., A. McGinty, B. Rector, R. C. Rowan, and L. D. White. 1990. Grazing and brush management on Texas rangelands - an analysis of management decisions. Texas Agric. Ext. Serv. College Station. Unnumbered Report. 22 p.

Kreuter, U.P., H. E. Amestoy, D.N. Ueckert, and W.A. McGinty, 2001. Adoption of Brush Busters: results of Texas county extension survey. J. Range Manage. 54:630-639.

Ladewig, H. and J. Beverly. 1988. South central Texas beef herd improvement plan 1983 -1987. Texas Agric. Ext. Serv. College Station. Unnumbered Report. $56 \mathrm{p}$.

McGinty, A. and D. N. Ueckert. 1995. Brush Busters - how to beat mesquite. Texas Agric. Ext. Serv. and Texas Agric. Exp. Sta. Leaflet L-5144.

McGinty, A. and D. N. Ueckert. 1996. Brush Busters-how to master cedar. Texas Agric. Ext. Serv. and Texas Agric. Exp. Sta. Leaflet L-5160.

McGinty, A., J. F. Cadenhead, W. Hamilton, W. C. Hanselka, D. Ueckert, and S. G. Whisenant. 2000. Chemical Weed and Brush Control Suggestions for Rangeland. Texas Agric. Ext. Serv. Bulletin B-1466.

Rowan, R. C. and J. R. Conner. 1995. Smallacreage livestock operators and resource management. Rangelands. 17:167-171.

Ueckert, D. N. and A. McGinty. 1997. Brush Busters - how to take care of pricklypear and other cacti. Texas Agric. Ext. Serv. and Texas Agric. Exp. Sta. Leaflet L-5171.

Ueckert, D. N. and A. McGinty. 1999a. Brush Busters-how to estimate costs for controlling pricklypear. Texas Agric. Ext. Serv. and Texas Agric. Exp. Sta. Leaflet L-5290.

Ueckert, D. N. and A. McGinty. 1999b. Brush Busters- how to estimate costs for controlling small mesquite. Texas Agric. Ext. Serv. and Texas Agric. Exp. Sta. Leaflet L-5291.

Ueckert, D. N. and A. McGinty. 1999c. Brush Busters-how to estimate costs for controlling small cedar. Texas Agric. Ext. Serv. and Texas Agric. Exp. Sta. Leaflet L-5292.

\section{Specifics On The Control Methods Selected}

All control methods selected for the Brush Busters program had to provide $70 \%$ or greater root kill of the treated plants - mesquite, cedar and pricklypear. Landowners were given several control methods for each plant.

Two methods were selected for the Brush Busters "How to Beat Mesquite" program. One was a leaf spray (i.e., high-volume foliar spray) which contains $0.5 \%$ clopyralid $+0.5 \%$ triclopyr (trade names Reclaim and Remedy, respectively; Dow AgroSciences LLC). The herbicides are applied in a water carrier with $0.25 \%$ surfactant. A small quantity $(1 / 3 \mathrm{oz} / \mathrm{gal})$ of Hi-Light spray-marking dye (Becker Underwood Inc.) is added to the leaf spray to help workers avoid missing plants or spraying the same plants twice.

The other mesquite control method was the stem spray (i.e., low-volume basal stem spray). The stem spray contains either 15 or $25 \%$ triclopyr in a diesel fuel carrier, the stronger concentration being recommended for mesquite stems with a basal diameter greater than 1.5 in., and/or rough bark. The stem spray is applied evenly, around the lower 12 in. of all mesquite stems, but not to the point of runoff.

Attention to proper spray equipment was a critical aspect of the Brush Busters program. A ConeJet 5500-X1 adjustable cone nozzle (Spraying Systems Co.) was recommended for applying the stem spray. Before Brush Busters was initiated, extensive field testing showed this nozzle minimizes herbicide use, cost, and grass damage, while maximizing deposition of the spray mixture on the target. The ConeJet 5500-X1 nozzle delivers only about $20 \%$ as much spray as nozzles that are commonly provided with backpack sprayers or hand-pressurized garden sprayers. A ConeJet 5500-X6 or $\mathrm{X} 8$ was recommended for the leaf spray.

Three methods were included in the Brush Busters "How to Master Cedar" program. (The name cedar was used instead of "juniper" because landowners in Texas more commonly know the plant by this name). One method was a leaf spray containing $1 \%$ picloram (Tordon $22 \mathrm{~K}$; Dow AgroSciences LLC ). The herbicide is applied in a water carrier with a surfactant $(0.25 \%)$ and spray-marking dye (1/3 oz./gal.).

The second method was called a soil spot spray. This method uses a spot gun or automatic syringe to apply a precise dose of undiluted hexazinone (Velpar L; DuPont Agricultural Products) on the soil surface beneath the cedar plant. The recommended rate is $2 \mathrm{cc}$ for every $3 \mathrm{ft}$ of height or canopy diameter for plants less than $6 \mathrm{ft}$ tall. The rate is doubled for redberry juniper over $6 \mathrm{ft}$ tall. Hand grubbing is also a recommended Brush Busters method for controlling cedars less than knee high.

The Brush Busters "How to Take Care of Pricklypear" program includes one herbicide and one mechanical control method. The herbicide method is a $\mathrm{pad} / \mathrm{stem}$ spray containing $1 \%$ picloram, applied in a water carrier with a surfactant $(0.25 \%)$ and spray-marking dye $(1 / 3 \mathrm{oz} . / \mathrm{gal}$.$) . The mechanical method$ is hand grubbing and stacking. 